\title{
Observing gas-catalyst dynamics at atomic resolution and single-atom sensitivity
}

S. Helveg ${ }^{1}$, C.F. Kisielowski ${ }^{2,3}$, J.R. Jinschek ${ }^{4}$, P. Specht ${ }^{5}$, G. Yuan $^{6}$, H. Frei ${ }^{2,6}$

${ }^{1}$ Haldor Topsøe A/S, Nymøllevej 55, DK-2800 Kgs. Lyngby, Denmark.

${ }^{2}$ Joint Center for Artificial Photosynthesis (JCAP), Lawrence Berkeley National Laboratory, 1 Cyclotron Road, Berkeley, CA 94720 (USA).

${ }^{3}$ National Center for Electron Microscopy, Lawrence Berkeley National Laboratory, 1 Cyclotron Road, Berkeley, CA 94720 (USA).

${ }^{4}$ FEI Company, Achtseweg Noord 5, 5651 GG Eindhoven, the Netherlands.

${ }^{5}$ Department of Materials Science and Engineering, University of California, Berkeley CA 94720 (USA).

${ }^{6}$ Physical Biosciences Division, Lawrence Berkeley National Laboratory, 1 Cyclotron Road, Berkeley, CA 94720 (USA).

\begin{abstract}
Transmission electron microscopy (TEM) has become an indispensable technique for studying heterogeneous catalysts. In particular, advancements of aberration-corrected electron optics and data acquisition schemes have made TEM capable of delivering images of catalysts with sub-Ångström resolution and single-atom sensitivity. Parallel developments of differentially pumped electron microscopes and of gas cells enable in situ observations of catalysts during the exposure to reactive gas environments at pressures of up to atmospheric levels and temperatures of up to several hundred centigrade. Here we outline how to take advantage of the emerging state-of-the-art instrumentation and methodologies to study surface structures and dynamics to improve the understanding of structure-sensitive catalytic functionality. The concept of using low electron dose-rates in TEM in conjunction with in-line holography and aberration-correction at low voltage (80 kV) is introduced to allow maintaining atomic resolution and sensitivity during in situ observations of catalysts. Benefits are illustrated by exit wave reconstructions of TEM
\end{abstract}


images of a nanocrystalline $\mathrm{Co}_{3} \mathrm{O}_{4}$ catalyst material acquired in situ during their exposure to either a reducing or oxidizing gas environment.

Corresponding authors are S.H. (sth@topsoe.dk) and C.F.K. (cfkisielowski@lbnl.gov).

Keywords: transmission electron microscopy, exit wave reconstruction, in situ studies, catalysis, water-splitting, nanocrystals, gas-surface interactions, dynamics.

\section{Introduction}

Heterogeneous catalysis plays a key role in chemical processes in the production of fuels and chemicals as well as in environmental protection technologies. Typically, the catalysts consist of high-surface-area solids onto which an active component is dispersed in the form of nanometer-sized particles. Hereby, the catalysts expose many different surface sites, which each are believed to contribute with distinct reactivity (Chorkendorff and Niemantsverdriet, 2007). To describe the catalytic functionality, it is therefore essential to have information about the size, shape and surface structure of the catalyst at the atomic level. With recent advancements in aberration-corrected electron optics as well as data acquisition and analysis schemes, (scanning) transmission electron microscopy techniques now enables observations of catalysts and other nanomaterials with a substantially reduced contrast delocalization, an enhanced resolution as well as a sensitivity that reach the ultimate single-atom level (Nellist and Pennycook, 1996; Contard et al., 2007; Su et al., 2008; Ortalan et al., 2010; Kisielowski et al., 2010; Hansen et al., 2011).

Procedures for synthesizing nanomaterials with well-defined shapes offer possibilities to address the structure-sensitive functionality in catalysis (An and Somorjai, 2012). The stability of the as-prepared nanomaterial is, however, not guaranteed when it is exposed to the actual catalytic reaction environments (An and Somojai, 2012; Topsøe, 2003). In reactive gas atmospheres, solid surfaces tend to restructure and adopt a geometric, compositional and electronic structure that is set by the environments (Topsøe, 2003; Tao and Salmeron, 2011). Strictly speaking, catalytic properties depend exclusively 
on reaction conditions in such a way that the active state only exists during catalysis. The realization that catalysts adjust dynamically to their environment has emerged from applying a variety of characterization techniques in conjunction with miniaturized reactors. Thereby, in situ or operando studies of single-crystal model surfaces or of nanoparticle catalysts, during exposure to catalytically relevant reactive gas conditions, are enabled (Prins and Koningsberger, 1998; Topsøe, 2003; Ertl et al. 2008; Tao and Salmeron, 2011; Buurmans and Weckhuysen, 2012).

In this context, in situ studies of catalysts using transmission electron microscopy (TEM), sometimes referred to as controlled atmosphere TEM or environmental TEM (ETEM), have greatly enriched our understanding of gas-solid interactions and their relevance to catalysis, and such studies are pursued by many research groups worldwide (Baker, 1979; Boyes and Gai, 1997; Helveg et al., 2004; Sharma and Crozier, 2005; Giorgio et al., 2006; Harutyunyan et al., 2009; Hansen et al., 2010; Yoshida et al., 2012; Li et al., 2013). Recently, single-atom sensitive electron microscopy has been demonstrated in situ during gas exposure to solid samples, but so far only the limited class of catalysts consisting of heavy metal atoms dispersed on light supports have been considered (Yoshida et al., 2013; Gai et al., 2014). Moreover, the atomic-scale observations obtained in situ are prone to invasive effects of the electron illumination. Thus, there is a need for further advancing electron microscopy of catalysts in environmental meaningful conditions toward single-atom sensitivity to allow studying the functional behavior of catalytic nanomaterials. Here we focus on recent advancements in TEM image acquisition schemes to outline possibilities for improving the image signal-to-noise ratios and reduce beam-induced artefacts.

\section{Reaction environments in transmission electron microscopes}

The use of TEM for in situ studies of catalysts is challenging partly due to the small mean-free path of the electrons in dense gases (Allinson, 1975; Butler and Hale, 1981). Therefore, the gas environment must be confined to the vicinity of the specimen. The confinement can be done employing either a differentially pumped microscope vacuum 
column, a closed cell equipped with electron-transparent windows or a micro-electromechanical system (MEMS) device.

In a differentially pumped microscope, the vacuum system is divided into separate volumes by incorporation of apertures along the microscope vacuum column (Fig. 1) (Doole, 1991; Boyes and Gai, 1997; Sharma and Crozier, 2005; Hansen et al., 2006). Gas is introduced into the volume hosting the catalyst specimen (referred to as the e-cell) and leaks out into the adjacent volumes that are connected to different vacuum pumps. Thereby, a gas pressure in the range $10^{-5} \mathrm{mbar}-20 \mathrm{mbar}$ can be confined in the specimen volume and does not contribute to electron scattering elsewhere. Alternatively, a closed cell, attached to sample holders, can contain the catalyst specimen and reaction environment and separates them from the microscope vacuum system. These different ecells allow for transmission of 80-400 keV electron beams and an image resolution limit of 0.10-0.31 nm during the exposure to gas pressures of up to ca. 20 mbar (Doole, 1991; Boyes and Gai, 1997; Sharma and Crozier, 2005; Hansen et al., 2006; Parkinson, 1989; Daulton et al., 2002; Giorgio et al., 2006; Jinschek and Helveg, 2012). More recently, ecells based on MEMS technology have started to appear, enabling a similar imaging resolution but at pressures up to the atmospheric level and above (Creemer et al., 2008; de Jonge et al., 2010; Yaguchi et al., 2011; Allard et al., 2012; Vendelbo et al., 2014).

As catalytic processes are typically executed at temperatures from room temperature and up to several hundred centigrade, the incorporation of sample heating in the e-cells is important as well. In the differential pumping system, heating can be accomplished by positioning the specimen in contact with a resistively heated filament or a MEMS-based heater (Butler and Hale, 1981; Kamino et al., 2005; Allard et al., 2009). An example of the technological edge provided by MEMS devices is given in Fig. 2, showing that sub-Ångström resolution (Fig. 2a) can be maintained up to $900{ }^{\circ} \mathrm{C}$ with minimal drift along (Fig. 2b) and orthogonal (Fig. 2c) to the electron beam direction. Likewise, for the window cells, a resistively heated filament can be implemented in the gas atmosphere (Giorgio et al., 2006) and, for the MEMS cell, electrodes integrated in the device allow for heating with the high drift-stability of the sample (Creemer et al., 2008; Allard et al., 2012). Moreover, laser illumination may also be applied for heat dissipation into the catalyst specimens (Mehraeen et al., 2013). 
The different e-cells provide complementary possibilities for in situ experiments in the transmission electron microscope (Hansen et al., 2006). The differential pumped sample volume requires significant instrument modifications and, therefore, a dedicated microscope that is robust for gas confinement. It is suited for investigations of the interaction of a limited number of gas types or fixed gas mixtures with solid surfaces and nanostructures due to the complex gas-flow patterns through the microscope. To fully exploit the benefits of aberration-corrected electron optics on resolution and sensitivity, the differential pumped cell seems advantageous because the electron beam is only affected by the added gas phase having a low atom density in the vicinity of the specimen. For the window and MEMS cells, electrons scatter by both the gas phase as well as the electrontransparent windows. As they contain a higher atom density confined close to the specimen plane, the additional electron scattering should contribute with enhanced contrast to the images. Moreover they may also contribute differently in terms of inelastic scattering and thus open up for alteration of reaction pathways implying that a corresponding reduction in the electron illumination may be needed for non-invasive observations. Thus, the differentially pumped system appears as the method of choice for in situ observations of catalysts at the ultimate resolution and sensitivity limits, whereas the window and MEMS cells are better suited for enabling in situ observations at pressures that are relevant to catalyst applications (Vendelbo et al., 2014).

\section{Enabling atomic-scale sensitivity and resolution in in situ electron microscopy}

The effect of a gas phase on TEM imaging sensitivity and resolution has been a subject of recent studies (Yoshida and Takeda, 2005; Jinschek and Helveg, 2012; Wagner et al., 2012; Bright et al., 2013, Suzuki et al., 2013). The differentially pumped e-cell, as implemented on the FEI Titan 80-300 ETEM, can accommodate gas environments at pressures of $10^{-5} \mathrm{mbar}-20 \mathrm{mbar}$, corresponding to a diatomic gas path for the electron beam of up to 75 atoms $/ \AA^{2}$ (Jinschek and Helveg, 2012). The gas phase should therefore be regarded as an additional random specimen, which can considerably enhance electron scattering and thereby offsets the background and blurs the image contrast. 
Figure 3 shows that the image intensity, and thus signal-to-noise ratio (SNR), attenuates with increasing pressure. A quantitative examination shows that the intensity attenuates exponentially for the conditions reported in (Jinschek and Helveg, 2012). The corresponding decay constant reflects that one total cross-section, including both inelastic and elastic electron-gas interactions, is sufficient to account for electron scattering to angles exceeding those accepted by the electron detection device (such as e.g. a charged coupled detector (CCD)) (Swann, 1972; Suzuki et al., 2013). The attenuation of the image intensity affects the achievable resolution because a recognizable image feature requires an image SNR above a certain value, SNR Rose (Rose, 1948). The intensity-dependent image resolution can be expressed (Rose, 2009):

(1) $d=\left(d_{i}^{2}+(S N R)^{2} /\left(C^{2} D\right)\right)^{1 / 2}$

The equation relates the achievable resolution $(d)$ to the native resolution of the microscope $\left(d_{i}\right)$, the image signal-to-noise ratio (SNR), the image contrast $(C)$, and the electron dose $(D)$. Using this relationship, the Rose criterion $S N R_{\text {Rose }} \geq 5$ and the contrast $C=1 / \mathrm{e}^{2}(\sim 0.14)$, an estimate can be made of the accumulated electron dose, $D$, necessary for making an atomic-scale feature distinguishable in a TEM image. In dynamic experiments this particular dose, $D_{\text {Rose }}$, have to be acquired within a chosen electron exposure time of the electron detector to maintain atomic resolution. This exposure time, $t_{\text {cutoff, }}$ is determined by the characteristic time-scale for the dynamic process under consideration, the drift of the specimen stage and the stability of the electron optics. Therefore, a finite $t_{\text {cutoff }}$ translates into a criterion on the corresponding electron dose-rate, $r$, or equivalently brightness of the microscope's electron source, which must exceed sufficiently high levels.

Unexpectedly, the electron dose $(D)$ and dose-rate $(r)$ affect the image resolution differently, as is illustrated in Fig. 3. The host microscope has an inherent resolution limit of $0.10 \mathrm{~nm}$ without gas admitted to the cell. Its resolution degrades as gas $\left(\mathrm{N}_{2}\right)$ is admitted to the e-cell at increasing pressures of up to $19.2 \mathrm{mbar}$. For the higher applied electron doserate (HD: $1^{*} 10^{4} \mathrm{e}^{-} / \AA^{2} \mathrm{~s}$ ), the resolution decreases further to $0.46 \mathrm{~nm}$, whereas it remains about $0.20 \mathrm{~nm}$ using a low dose-rate (LD: $\left.1 * 10^{2} \mathrm{e}^{-} / \AA^{2} \mathrm{~s}\right)$. Moreover, Fig. 3 shows that increasing the exposure time (10 s) for the LD condition further results in an improved resolution of $0.12 \mathrm{~nm}$, which is close to the inherent microscope resolution, even at 19 
mbar. In contrast, shortening the exposure time for the HD condition does not improve the deteriorated image resolution. These findings are surprising because it is expected from equation 1 that only an accumulated electron dose determines the signal-to-noise ratio and thereby resolution. The finding that the image resolution differs markedly even for the same electron dose demonstrates that the gas is not only acting as an intensity (electron dose) attenuator but makes the high spatial TEM resolution dependent on the electron dose-rate (Jinschek and Helveg, 2012). Specifically, the results demonstrate that the imaging performance of the state-of-the-art differentially pumped cells is not chromatically limited, but rather determined by both the electron dose and the electron dose-rate.

Similarly, an electron dose-rate dependent TEM performance was recently reported to affect the high-resolution TEM image contrast by a factor of two or more (Barton et al., 2012; Kisielowski et al., 2013) and the energy-loss near-edge structure (Jiang and Spence, 2012). Here, the dose-rate dependent resolution was related to electron beaminduced specimen excitations. It is argued that specimen excitations by the electron beam are naturally accompanied by relaxation effects leading to dynamic responses of the atoms in the sample. The level of excitation can be tuned by the electron dose-rates if successive electrons are delivered at time intervals that are comparable to or longer than the time constants of the possible relaxation processes. Importantly, the excitation contribution to the image contrast becomes minimal at sufficiently low dose-rates when reversible specimen relaxations occur between successively delivered electrons (Kisielowski et al., 2013). In high electron dose-rate conditions, thermal excitations contribute to atom displacements but also electronic excitation and ionization damage receive greater impact, depending on the type of material under investigation (Egerton et al., 2004).

The present discussion is summarized in Fig. 4, which illustrates a relation between the accumulated electron dose, the electron dose-rate and the exposure time. The accumulated electron dose must exceed the threshold value $D_{\text {Rose }}$ to ensure the visibility of object features at a desired resolution. On the other hand, the electron dose-rate must also be sufficiently low to keep sample excitations at a non-invasive level. For simplicity, it is here assumed that a single threshold dose-rate $r_{\max }$ sets an upper limit for a noninvasively delivered electron dose for a given exposure time. The exposure time $t_{\text {cutoff }}$ limits 
the accumulation of electron dose because of the dynamic process under investigation, the specimen drift, and the microscope stability. Furthermore, the primary electron energy must be considered as well. On one hand, it allows tuning ionization and displacement events (Egerton et al., 2004), and, on the other hand, it controls transmission and contrast such that lowering the beam energy reduces transmission through a gas phase and enhances the object contrast. Thus, all in situ experiments should be optimized to ensure imaging with parameter sets that allow maintaining sample integrity while providing a largest amount of information, which often requires a largest possibly resolution (blue area in Fig. 4).

It is important to realize that the parameter space in Fig. 4 depends on the catalyst and the reaction conditions. However, the parameter space is difficult to predict and, therefore, an experimental approach is necessary to accommodate and control the effect of the electron beam (Simonsen et al., 2010). In particular beam-sample interactions in an in situ experiment are often undetectable in their early stages because most atomically resolved images depict only atom columns containing many atoms instead of single atoms. Nonetheless the progress in electron microscopy was extraordinary over the past decade and have enhanced image signal-to-noise ratios such that it has become feasible to detect single atoms across the Periodic Table of elements (Kisielowski et al., 2008), assisted by in-line holography with variable dose-rate and voltages (Barton et al., 2012). The in-line holography provides new perspectives for imaging pristine catalyst structures and even single molecules (Specht et al., 2011; Barton et al., 2012). As these are nonperiodic structures, the SNR is difficult to enhance by spatially averaging a motif in single images. Instead, the in-line holography averages a series of consecutive acquired images of the catalyst. This approach is beneficial over a simple averaging of an image series recorded at fixed optical conditions, because residual aberrations are corrected and the largest amount of structural information becomes available (Jinschek et al., 2011). The inline holography method is applicable to monitor dynamic processes with a characteristic time-scale that allows for the multiple, consecutive acquisitions of images of the same structure. However, this concept is not yet exploited in in situ transmission electron microscopy. The present contribution is the first of such kind and will show its benefits

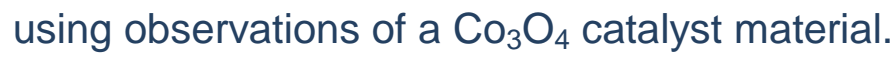




\section{Atomic structure and dynamics of a $\mathrm{Co}_{3} \mathrm{O}_{4}$ catalyst surface in $\mathrm{CO}$ and $\mathrm{H}_{2} \mathrm{O}$}

Cobalt-based catalysts are applied in the Fischer-Tropsch process (Dry, 2002) or for water oxidation (Jiao and Frei, 2009). The catalyst materials have previously been subject to in situ TEM studies with an emphasis on hydrogen reduction of $\mathrm{Co}_{3} \mathrm{O}_{4}$ into Co (Dehghan et al., 2011; Ward et al., 2013). Such studies represent the current state-of-theart, but further contrast and SNR advancements are needed to acquire knowledge at the single-atom level, as it has been mentioned before. A first demonstration of such advancements is illustrated here by the observations of a nanocrystalline $\mathrm{Co}_{3} \mathrm{O}_{4}$ catalyst material during the exposure to $\mathrm{CO}$, as a reducing gas, or to $\mathrm{H}_{2} \mathrm{O}$, as an oxidizing gas environment.

The $\mathrm{Co}_{3} \mathrm{O}_{4}$ catalyst material was grown by a surfactant-assisted solvothermal method as previously reported in (Agiral et al., 2013). Typically, $0.2 \mathrm{~g}$ of $\mathrm{Co}\left(\mathrm{CH}_{3} \mathrm{COO}\right)_{2} \cdot 4 \mathrm{H}_{2} \mathrm{O}$ (Fluka) was dissolved in ethanol/water mixed solvent $(23 \mathrm{~mL}+2 \mathrm{~mL})$

and $1 \mathrm{~g}$ of Cetyl-trimethylammonium bromide (CTAB, high purity grade AMRESCO) was added under sonication. The mixture was sonicated in air for $15 \mathrm{~min}$, and then $2 \mathrm{~mL}$ of $30 \%$ ammonia was added under vigorous stirring. The slurry was transferred into a Teflonlined stainless steel autoclave (Parr Instrument Company, acid digestion vessel) with a capacity of $125 \mathrm{~mL}$, sealed, and heated up to $150{ }^{\circ} \mathrm{C}$ for $3 \mathrm{~h}$. After the solvothermal synthesis, the autoclave was cooled to room temperature and the black precipitates were washed with acetone, water, and ethanol by centrifugation-redispersion to remove the excess ions and surfactant molecules. The final surfactant free $\mathrm{Co}_{3} \mathrm{O}_{4}$ nanoparticles were collected by centrifugation, dispersed in ethanol, and stored at room temperature. The nanoparticles are single crystalline $\mathrm{Co}_{3} \mathrm{O}_{4}$ with an average size of $5 \mathrm{~nm}$.

The electron microscopy observations were obtained using a FEI Titan 80-300 ETEM equipped with a differentially pumped e-cell (Jinschek and Helveg, 2012). The microscope was operated with primary electron energy of $80 \mathrm{keV}$, which results in the largest contrast for the aberration-corrected Titan-type of microscopes. A CEOS spherical aberration $\left(\mathrm{C}_{\mathrm{s}}\right)$ corrector for the objective lens in transmission electron microscopy mode was tuned prior to the observations on an $\mathrm{Au} / \mathrm{C}$ cross-grating specimen with a spherical aberration coefficient in the range of $-15 \mu \mathrm{m}$. Furthermore, the microscope is equipped 
with additional instrumentation for monitoring the reaction environment, including a postcolumn GATAN Image Filter (GIF) Tridiem 863 for electron energy loss spectroscopy (EELS).

The nanocrystalline $\mathrm{Co}_{3} \mathrm{O}_{4}$ sample was examined under the base vacuum of the microscope and in situ during exposure to either a reducing gas (CO) or an oxidizing gas $\left(\mathrm{H}_{2} \mathrm{O}\right)$. The sample was kept at room temperature during all observations. The $\mathrm{CO}$ was introduced into the e-cell through a carbon filter to prevent $\mathrm{Ni}$ contamination from nickel carbonyl residues in the gas, and the $\mathrm{H}_{2} \mathrm{O}$ was purified by pump-freeze-thaw cycles prior to the introduction (Vesborg et al., 2009). Figure 5 shows electron energy loss spectra of $\mathrm{CO}$ and $\mathrm{H}_{2} \mathrm{O}$ from their low energy loss region, which reflects a characteristic fingerprint for the different types of gases (Crozier and Chenna, 2011).

The nanocrystalline $\mathrm{Co}_{3} \mathrm{O}_{4}$ material was dispersed on a lacey carbon film (Fig. 6a) and examined at high magnification in the electron microscope. Specifically, focal series of 30 high-resolution TEM images were acquired with an exposure time of 1-5 seconds per image and a dose-rate as indicated in the following. A dose-rate was obtained as the CCD pixel count rate calibrated toward a nominal measurement at the fluorescent screen of the microscope. The images in a series cover a focal range roughly from $80 \mathrm{~nm}$ to $-20 \mathrm{~nm}$. The focal image series were subsequently aligned with a precision of a few pm (Kisielowski et al., 2014), and the exit wave was reconstructed using the GerchbergSaxton algorithm (Gerchberg, Saxton, 1972), as implemented in the MacTempas software (www.totalresolution.com). With the drift-stability of MEMS-based heaters as demonstrated in Fig. 2c, this method should in principle be applicable to catalysts operating at elevated temperatures of up to $900^{\circ} \mathrm{C}$. Figure $6 \mathrm{~b}, \mathrm{c}$ shows the amplitude and phase of an exit wave of the $\mathrm{Co}_{3} \mathrm{O}_{4}$ material during the exposure to $\mathrm{CO}$. Both images constitute an in-line hologram, and its Fourier transformation provides a nanodiffraction pattern that identifies the crystal space group to be \#227 (Fig. 6d,e). It is emphasized that the nanodiffraction pattern differs from the Fourier transform of a single high-resolution TEM image because the Friedel symmetry is not imposed and non-centrosymmetric intensities are present in the pattern (Fig. 6e). Moreover, the holographic reconstruction procedure solves the phase problem and atom positions are marked in the phase images by bright appearances. 
Important advantages for in situ observations become evident if this electron holography method is considered with variable electron dose-rates. A demonstration is given in Fig. 7 showing $\mathrm{a} \mathrm{Co}_{3} \mathrm{O}_{4}$ nanocrystal during exposure to 2.1 mbar CO. Fig. $7 \mathrm{a}$ shows a single image from a time series that is acquired with $700 \mathrm{e}^{-} / \AA^{2} \mathrm{~s}$ at a constant focus. All images are provided in the Supplementary Movie. A careful inspection of the individual frames reveals that the surface structure of the nanocrystal fluctuates greatly as a result of uncontrolled atom or atom column displacements. The effect is attributed to sample excitations caused by the electron beam and is in line with common observations in high performance electron microscopes that employ high brightness electron beams to detect single atoms (McBride et al, 2013; Kisielowski et al., 2013). Many surface alterations are observable in the Supplementary Movie, and two of them are indicated by the white arrows in Fig. 7a. Successively, an additional focus series of 30 images of the same area was recorded at the electron dose-rate of $700 \mathrm{e}^{-} / \AA^{2} \mathrm{~s}$ to reconstruct the exit wave. Since the exit wave reconstruction involves image averaging that effectively accumulates electron dose, the resulting phase image in Fig. $7 b$ obtains a greatly enhanced SNR. However, atom or column motion is now easily recognized by a streak-like image blur as part of the surface (white arrow, Fig. 7b). Clearly, information about the pristine catalyst surface is thereby lost. Alternatively, the electron dose-rate can be reduced to $30 \mathrm{e}^{-} / \AA^{2} \mathrm{~s}$ as in Fig. 7c. Consequently, information about the sample is now greatly compromised because the single images are dominated by noise (Fig. 7c). However, the exit wave reconstruction procedure is currently used for dose-rates as low as 10 - 100 e/ $\AA^{2} s$ for which image alignment still remains feasible (Barton et al., 2012; Kisielowski et al., 2013). Thus, exit wave reconstruction certainly allows for recovery of image SNR and sample visibility. The phase of the exit wave function reconstructed from low dose-rate images is shown in Fig. 7d. In fact, an improved quality of the low dose-rate phase image (Fig.7d) becomes evident if compared to the phase image obtained from the high dose-rate images (Fig. 7b): First, a more detailed contrast pattern across the bulk part of the nanocrystal is obtained, which is absent under the high dose-rate condition. This contrast pattern reflects a corrugated surface structure of the nanocrystal. Second, for the nanocrystal surface observed in profile, the streak-like contrast is now quenched, and the surface appears sharp revealing a stepped morphology. Beam-induced atom motion therefore seems largely suppressed, which additionally aids phase recovery at this low 
electron dose-rate (Barton et al., 2012; Kisielowski et al., 2013). Consequently, the combination of a low electron dose-rate with exit wave reconstruction enables observations of the pristine state of a catalyst surface in a gaseous reaction environment. In this case, the catalyst surface has a rough atomic structure in the reducing $\mathrm{CO}$ gas. Such information about nanocrystal surfaces is currently difficult to obtain by other characterization techniques with this level of detail.

In Fig. 8, the $\mathrm{Co}_{3} \mathrm{O}_{4}$ catalyst material is inspected under vacuum (a-c) and during exposure to $\mathrm{CO}(\mathrm{d}-\mathrm{f})$. In both environments, single images are recorded before (Fig. 8a,d) and after (Fig. 8c,f) the focal series acquisition. The reconstructed phases of the electron exit wave functions are depicted in Fig. 8b,e. All images were acquired using an intermediate dose-rate of $300 \mathrm{e}^{-} / \AA^{2} \mathrm{~s}$. Still, at this dose-rate, the individual images (Fig. 8 a,c) have a noise level that masks a surface reconstruction of the nanocrystal, but the reconstruction becomes visible in the phase image (Fig. 8b) due to increased SNR. Specifically, Fig. 9 addresses the SNR of the atom columns of the surface reconstruction in Fig. 8b. The linescan shows the phase signal strength of $\sim 0.14$ radian with a noise level of $\sim 0.02$ radian, corresponding to a SNR of $\sim 7$. Since all the crystallites are stacked in a random fashion and have similar projected shape in the TEM images, their projected width orthogonal to and depth along the electron beam direction are likely comparable. Therefore, the crystallite in Fig. 9 has atomic columns at the surface containing about 5 atoms. Thus, the estimated SNR exceeds one, which allows for detection of single atoms. A comparison of the phase images of the same particle in vacuum (Fig. 8b) and in $\mathrm{CO}$ (Fig. 8e) shows that $\mathrm{CO}$ tends to transform the extended reconstruction of the $\mathrm{Co}_{3} \mathrm{O}_{4}$ surface into a more compact structure. Despite the intermediate electron dose-rate of 300 $\mathrm{e}^{-} / \AA^{2} \mathrm{~s}$ was employed, the images recorded before and after the focal series acquisition are similar and a recognizable displacement of surface atoms of the kind, as seen in Fig. 7, was also not observed. These observations suggest that the intermediate dose-rate is still adequate. The transformation is therefore believed to reflect the interaction of $\mathrm{CO}$ with $\mathrm{Co}_{3} \mathrm{O}_{4}$ surfaces, although the detailed chemical reactions still have to be addressed in detail.

Interestingly, the addition of water vapor transforms the surface of the $\mathrm{Co}_{3} \mathrm{O}_{4}$ catalyst to a smoother appearance as shown in Fig. 10a,b. Again such subtle changes of 
the surface structure are noise limited in the single images, as seen in Fig. 10c,f. In some cases, even a complete coverage of the catalyst surface with amorphous materials occurred as a result of increasing water vapor pressure, as evidenced by Fig. 10d,e. Importantly, the observation of amorphous layers demonstrates that the presented imaging technique has sensitivity to surfaces, even in plane-view configurations. However, upon continued exposure to $\mathrm{H}_{2} \mathrm{O}$, an amorphous overlayer structure grew rapidly (Fig. 11). Because the overlayers were absent in TEM images of $\mathrm{Co}_{3} \mathrm{O}_{4}$ surfaces acquired in other places of the sample that remained unexposed to the electron beam, the formation of the amorphous layers is accelerated under electron illumination. It remains to be addressed what the chemical composition of those layers are, and why they form only during exposure of the sample to water vapor. A formation of amorphous surface layers in the electron microscope during observation is a common phenomenon. It is possible that further optimization of the electron illumination along the present guidelines may help understanding and controlling such effects as well.

\section{Outlook}

In the past, transmission electron microscopy of catalyst surfaces in their pristine working states at elevated temperatures and pressures typically lacked the signal-to-noise ratio that is required to detect single atoms and molecules. An instrument operated at Haldor Topsøe A/S was used to implement in-line holography at variable electron dose-rates and energies to demonstrate for the first time that such investigations are now possible because of a marked gain in sensitivity and control of beam-sample interactions. This research expands the applicability of transmission electron microscopy in chemical sciences and builds a foundation for "live" observations of structure-sensitive functional behavior at the single-atom level and in chemically meaning environments.

\section{Acknowledgements}

TEM measurements were conducted at the electron microscopy facility at Haldor Topsøe A/S. The authors gratefully acknowledge Sven Ullmann (Haldor Topsøe A/S) for support during the experiments. The data acquisition and interpretation were supported by the Joint Center for Artificial Photosynthesis, a DOE Energy Innovation Hub, supported 
through the Office of Science of the U.S. Department of Energy under Award Number DESC0004993. Co oxide crystals were prepared by work supported by the Director, Office of Science, Office of Basic Energy Sciences, Division of Chemical, Geological and Biosciences of the U.S. Department of Energy under Contract No. DE-AC02-05CH11231.

\section{References}

Agiral, A., Soo, H. S., Frei, H., 2013, Visible Light Induced Hole Transport from Sensitizer to $\mathrm{Co}_{3} \mathrm{O}_{4}$ Water Oxidation Catalyst across Nanoscale Silica Barrier with Embedded Molecular Wires. Chem. Mater. 25, 2264-2274.

Allard, L.F., Bigelow, W.C. Jose-Yacaman, Nackashi, D., M., Damiano, Mich, S.E., 2009. A New MEMS-Based System for Ultra-High-Resolution Imaging at Elevated Temperatures. Micro. Res. Tech. 72, 208-215.

Allard, L.F., Overbury, S.H., Bigelow, W.C., Katz, M.B., Nackashi, D.P., Damiano, J., 2012. Novel MEMS-Based Gas-Cell/Heating Specimen Holder Provides Advanced Imaging Capabilities for In Situ Reaction Studies. Microsc. Microanal., 18, 656-666.

Allinson, D.L., 1975. Environmental devices in electron microscopy, in: Hayat, M.A. (Ed.), Principles and techniques in electron microscopy, biological applications, vol.5. Van Nostrand Reinhold Company, New York, pp. 62-113.

An, K., Somorjai, G.A., 2012. Size and Shape Control of Metal Nanoparticles for Reaction Selectivity in Catalysis. ChemCatChem 4, 1512-1524.

Baker, R.T., 1979. In Situ Electron Microscopy Studies of Catalyst Particle Behavior. Catal. Rev.-Sci. Eng. 19, 161-209.

Barton, B. Buonsanti, R., Dong, A., Milliron, D., Hansen, L.P., Helveg, S., Jiang B., Kisielowski, C., 2012. The challenge of imaging hard/soft matter interfaces at atomic resolution. Microsc.Microanal. 18, 1606-1607.

Barton, B. Jiang, B., Song, C., Specht, P., Calderon, H., Kisielowski, C., 2012. Atomic Resolution Phase Contrast Imaging and In-Line Holography Using Variable Voltage and Dose Rate. Microsc. Microanal. 18, 982-994.

Boyes, E.D., Gai, P.L., 1997. Environmental high resolution electron microscopy and applications in chemical science. Ultramicroscopy 67, 219-232.

Bright, A.N., Yoshida, K., Tanaka, N., 2013. Influence of total beam current on HRTEM image resolution in differentially pumped ETEM with nitrogen gas. Ultramicroscopy 124, 46-51. 
Buurmans, I.L.C., Weckhuysen, B.M., 2012. Heterogeneities of individual catalyst particles in space and time as monitored by spectroscopy. Nature Chem. 4, 873-886.

Butler, E.P., Hale, K.F., 1981. Dynamic Methods in the Electron Microscope, in Practical Methods in Electron Microscopy, vol. 9 (ed. A.M. Glauert). North Holland Publishing Company.

Chorkendorff, I., Niemantsverdriet, J.W., 2007. Concepts of Modern Catalysis and Kinetics. Wiley-VHC GmbH \& Co. KGaA, Weinheim.

Contard, L.C., Chang, L.-Y., Hetherington, C.J.D., Kirkland, A.I., Ozkaya, D., DuninBorkowski, R.E., 2007. Aberration-Corrected Imaging of Active Sites on Industrial Catalyst Nanoparticles. Angew. Chemie Int. Ed. 46, 3683-3685.

Creemer, J.F., Helveg, S., Hoveling, G.H., Ullmann, S., Molenbroek, A.M., Sarro, P.M, Zandbergen, H.W., 2008. Atomic-scale electron microscopy at ambient pressure. Ultramicroscopy 108, 993-998.

Crozier, P.A., Chenna, S., 2011. In situ analysis of gas composition by electron energyloss spectroscopy for environmental transmission electron microscopy. Ultramicroscopy $111,177-185$.

Daulton, T.L., Little, B.J., Kim, J.W., Newell, S., Lowe, K., Furukawa, Y., Jones-Meehan, J., Lavoi, D.L., 2002. Quantitative Environmental Cell - Transmission Electron Microscopy: Studies of Microbial $\mathrm{Cr}(\mathrm{VI})$ and $\mathrm{Fe}(\mathrm{III})$ Reduction. JEOL News 37, 6-13.

Dehghan, R., Hansen, T.W., Wagner, J.B., Holmen, A., Rytter., E., Borg, Ø., Walmsley, 2011. In-Situ Reduction of Promoted Cobalt Oxide Supported on Alumina by Environmental Transmission Electron Microscopy. Catal. Lett. 141, 754-761.

De Jonge, N., Bigelow, W.C., Veith, G.N., 2010. Atmospheric Pressure Scanning Transmission Electron Microscopy. Nanoletters 10, 1028-1031.

Doole, R.C., Parkinson, G.M., Stead, J.M., 1991. A high resolution gas reaction cell for the JEM 4000. Inst. Phys. Conf. Ser. 119, 157-160.

Dry, M. E., 2002. The Fischer-Tropsch process: 1950-2000. Catal. Today 71, 227-241.

Egerton, R.; Li, P.; Malac, M., 2004. Radiation damage in TEM and SEM. Micron 35, 399409.

Ertl., G., Knözinger, H., Schüth, F., Weitkamp, J. (Eds.), 2008. Handbook of Heterogeneous Catalysis, 2nd ed. VCH-Wiley, Weinheim.

Gai, P.L., Lari, L., Ward, M.R., Boyes, E.D., 2014, Visualisation of single atom dynamics and their role in nanocatalysts under controlled reaction environments. Chem. Phys. Lett. 592, 355-359. 
Gerchberg, R.W., Saxton, W.O., 1972. A practical algorithm for the determination of the phase from image and diffraction plane pictures. Optik 35, 237-246.

Giorgio, S., Sao Joao, S., Nitsche, S., Chaudanson, D., Sitja, G., Henry, C.R., 2006. Environmental electron microscopy (ETEM) for catalysts with a closed E-cell with carbon windows. Ultramicroscopy 106, 503-507.

Hansen, P.L., Helveg, S., Datye, A.K., 2006. Atomic-Scale Imaging of Supported Metal Nanocluster Catalysts in the Working State. Adv. Catal. 50, 77-94.

Hansen, T.W., Wagner, J.B, Dunin-Borkowski, R., 2010. Aberration corrected and monochromated environmental transmission electron microscopy: challenges and prospects for materials science. Mat. Sci. Technol. 26, 1338-1344.

Hansen, L.P., Ramasse, Q.M., Kisielowski, C., Brorson, M., Johnson, E., Topsøe, H., Helveg, S., 2011. Atomic-Scale Edge Structures on Industrial-Style $\mathrm{MoS}_{2}$ Nanocatalysts. Angew. Chemie Int. Ed. 50, 10153-10156.

Harutyunyan, A.R., Chen, G., Paronyan, T.M., Pigos, E.M., Kuznetsov, O.A. Hewaparakrama, K., Kim, S.M., Zakharov, D., Stach, E.A., Sumanasekera, G.U. 2009. Preferential Growth of Single-Walled Carbon Nanotubes with Metallic Conductivity. Science 326, 116-120.

Helveg, S., López-Cartes, C., Sehested, J., Hansen, P.L., Clausen, B.S., Rostrup-Nielsen, J.R., Abild-Pedersen, F., Nørskov, J.K., 2004. Atomic-scale imaging of carbon nanofibre growth. Nature 427, 429-429.

Jiang, N., Spence, J.C.H., 2012. On the dose-rate threshold of beam damage in TEM. Ultramicroscopy 113, 77-82.

Jiao, F., Frei, H., 2009. Nanostructured Cobalt Oxide Clusters in Mesoporous Silica as Efficient Oxygen-Evolving Catalysts. Angew. Chemie. Int. Ed. 48, 1841-1844.

Jinschek, J.R., Yucelen, E., Calderon, H.A., Freitag B., 2011. Quantitative atomic 3-D imaging of single / double sheet graphene structure, Carbon 49, 556-562.

Jinschek, J.R., Helveg, S., 2012. Image resolution and sensitivity in an environmental transmission electron microscope. Micron 43, 1156-1168.

Kamino, T., Yaguchi, T., Konno, M., Watabe, A., Marukawa, T., Mina, T., Kuroda, K., Saka, H., Arai, S., Makino, H., Suzuki, Y., Kishita, K., 2005. Development of a gas injection/specimen heating holder for use with transmission electron microscope. J. Electron. Microsc. 54, 497 -503.

Kisielowski, C. Freitag., B., Bischoff M., van Lin, H., Lazar, S., Knippels, G., Tiemeijer, P., van der Stam, M., von Harrach, S., Stekelenburg, M., Haider, M., Uhleman, S., Müller, H., Hartel, P., Kabius, B., Miller, D., Petrov, I. Olson E.A., Donchev, T., Kenik E.K., Lupini, A.P., Bentley, J., Pennycook, S.J., Anderson, I.M., Minor, A.M., Schmid, A.K., Duden, T., 
Radmilovic, V., Ramasse, Q.M., Watanabe, M., Erni, R., Stach, E.A., Denes, P., Dahmen, U., 2008. Detection of Single Atoms and Buried Defects in Three Dimensions by Aberration-Corrected Electron Microscope with 0.5-Å Information Limit. Microsc. Microanal. 14, 454-462.

Kisielowski, C., Ramasse, Q.M., Hansen L.P., Brorson, M., Carlsson, A., Molenbroek, A.M., Topsøe, H., Helveg, S., 2010. Imaging $\mathrm{MoS}_{2}$ Nanocatalysts with Single-Atom Sensitivity, Angew. Chemie Int. Ed. 49, 2708-2710.

Kisielowski, C., Wang, L.-W., Specht, P., Kang, J.H., Cieslinski, R., 2013. Probing the onset of functional behavior by exciting reversible atom displacements using variable voltages and dose rates, Microsc. Microanal. 19, $1210-1211$.

Kisielowski, C., Wang, L.-W., Specth, P., Calderon, H.A., Barton, B., Jiang, B., Kang, J.H., Cielinski, R., 2013. Real-time sub-Ångstrom imaging of reversible and irreversible conformations in rhodium catalysts and graphene. Phys. Rev. B. 024305.

Kisielowski. C, Specht, P., Gygax, S.M., Barton, B., Calderon, H.A., Kang, J.-H., Cieslinski R., 2014. Instrumental requirements for the detection of electron beam-induced object excitations at the single atom level in high-resolution transmission electron microscopy. Micron, this volume.

Li, W.-Z., Kovarik, L., Mei, D., Liu, J., Wang, Y., Peden, C.H.F., 2013. Stable platinum nanoparticles on specific $\mathrm{MgAl}_{2} \mathrm{O}_{4}$ spinel facets at high temperatures in oxidizing atmospheres. Nature Communications 2481.

McBride, J.R., Pennycook, T.J., Pennycook, S.J., Rosenthal, S.J., 2013. The Possibility and Implications of Dynamic Nanoparticle Surfaces. ACS Nano 7, 8358-8365.

Mehraeen, S., McKeown, J.T., Deshmukh, P.V., Evans, J.E., Abellan, P., Xu, P., Reed, B.W., Taheri, M.,L., Fischione, P.E., Browning, N.D., 2013. A (S)TEM Gas Cell Holder with Localized Laser Heating for In Situ Experiments. Microsc. Microanal. 19, 470-478.

Nellist, P.D., Pennycook, S.J., 1996. Direct Imaging of the Atomic Configuration of Ultradispersed Catalysts. Science 274, 413-415.

Ortalan, V., Uzun, A., Gates, B.C., Browning, N.D., 2010. Towards full-structure determination of bimetallic nanoparticles with an aberration-corrected electron microscope. Nature Nanotech 5, 843-847.

Parkinson, G.M., 1989. High Resolution, In-Situ Controlled Atmosphere Transmission Electron Microscopy (CATEM) of Heterogeneous Catalysts. Catal. Lett. 2, 303 -308.

Prins, R., Koningsberger, D. C., 1998. X-ray Absorption: Principles, Applications, Techniques of EXAFS, SEXAFS, and XANES, (Eds.: D. C. Koningsberger and R. Prins), New York, Wiley, p. 321.

Rose A., 1948. Television Pickup Tubes and the Problem of Vision, Advances in Electronics and Electron Physics 1, 131-166. 
Rose, H., 2009. Future trends in aberration-corrected electron microscopy. Phil. Trans. R. Soc. A. $367,3809-3823$.

Sharma, R., Crozier, P.A., 2005. Environmental transmission electron microscopy in nanotechnology, in:Yao, N., Wang, Z.L. (eds.), Handbook of microscopy for nanotechnology. Kluwer Academic Publishers, New York, pp. 531-565.

Simonsen, S.B. Chorkendorff, I., Dahl, S., Skoglundh, M., Sehested, J., Helveg, S., 2010. Direct Observation of Oxygen-Induced Platinum Nanoparticle Ripening Studied by In Situ TEM. J. Am. Chem. Soc. 132, 7968-7975.

Specht, P., Gulotty Jr., R.J., Barton, D., Cieslinski, R., Rozeveld, S., Kang, J.H., Dubon, O.D., Kisielowski, C., 2011. Quantitative Contrast Evolution of an Industry-Style Rhodium Nanocatalyst with Single Atom Sensitivity. ChemCatChem 3, 1034-1037.

Su, D., Jacob, T., Hansen, T.W., Wang, D., Schlögl, R., Freitag, B., Kujawa, S., 2008. Surface Chemistry of Ag Particles; Identification of Oxide Species by Aberration-Corrected TEM and by DFT Calculations. Angew. Chemie Int. Ed. 47, 5005-5008.

Suzuki, M., Yaguchi, T., Zhang, X.F., 2013. High-resolution environmental transmission electron microscopy: modelling and experimental verification. Microscopy 62, 437-450.

Swann, P.R., 1972. High voltage microscopy studies of environmental reactions, in: Thomas, G. (Ed.), Electron Microscopy and Structure of Materials. University of California Press, Los Angeles, pp. 878-904.

Tao, F.F., Salmeron, M., 2011. In Situ Studies of Chemistry and Structure of Materials in Reactive Environments. Science 331, 171-174.

Topsøe, H., 2003. Developments in operando studies and in situ characterization of heterogeneous catalysts. J. Catal. 216, 155-164.

Vendelbo, S.B., Elkjær. C.F., Falsig, H., Puspitasari, I., Dona, P., Mele, L., Morana, B., Nelissen, B.J., van Rijn, R., Creemer, J.F., Kooyman, P., Helveg, S., 2014. Visualisation of oscillatory behaviour of Pt nanoparticles catalysing $\mathrm{CO}$ oxidation. Nature Materials. DOI: $10.1038 /$ nmat4033

Vesborg, P.C.K., Chorkendorff, I., Knudsen, I., Balmes, O., Nerlov, J., Molenbroek, A.M., Clausen, B.S., Helveg, S., 2009. Transient behavior of $\mathrm{Cu} / \mathrm{ZnO}$-based methanol synthesis catalysts. J. Catal. 262, 65-72.

Wagner J.B., Cavalca, F., Damsgaard, C.D., Duchstein, L.D.L., Hansen, T.W., 2012. Exploring the environmental transmission electron microscope. Micron 43, 1169-1175.

Ward, M.R., Boyes, E.D., Gai., P.L., 2013. In Situ Aberration-Corrected Environmental TEM: Reduction of Model $\mathrm{Co}_{3} \mathrm{O}_{4}$ in $\mathrm{H}_{2}$ at the Atomic Level. ChemCatChem 5, 2655-2661. 
Yaguchi, T., Suzuki, M., Watabe, A., Nagakubo, Y., Ueda, K., Kamino, T., 2011.

Development of a high temperature-atmospheric pressure environmental cell for highresolution TEM. J. Electron Microsc. 60, 217-225.

Yoshida, H., Takeda, S., 2005. Image formation in a transmission electron microscope equipped with an environmental cell: Single-walled carbon nanotubes in source gases. Phys. Rev. B 72, 195428 1-7.

Yoshida, H., Kuwauchi, Y., Jinschek, J.R., Sun, K., Tanaka, S., Kohyama, M., Shimada, S., Haruta, M., Takeda, S., 2012. Visualizing Gas Molecules Interaction with Supported Nanoparticulate Catalysts at Reaction Conditions. Science 335, 317-319.

Yoshida, K., Tominaga, T., Hanatani, T., Tagami, A., Sasaki, Y., Yamasaki, J., Saitoh, K., Tanaka, N., 2013. Key factorsfor the dynamic ETEM observation of single atoms. Microscopy 62, 571-582.
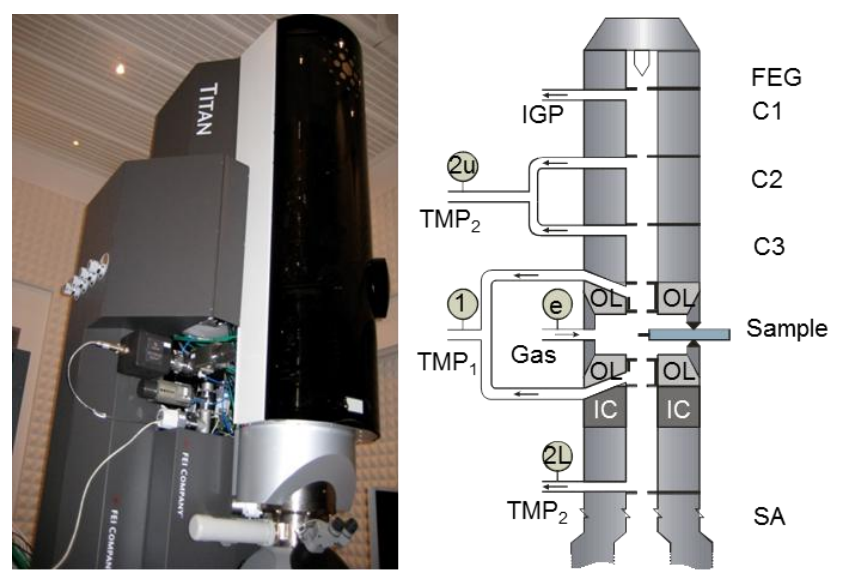

Figure 1. Photo of a FEI Titan 80-300 ETEM and a sketch of its differential pumping system. Adapted from (Jinschek and Helveg, 2012). 

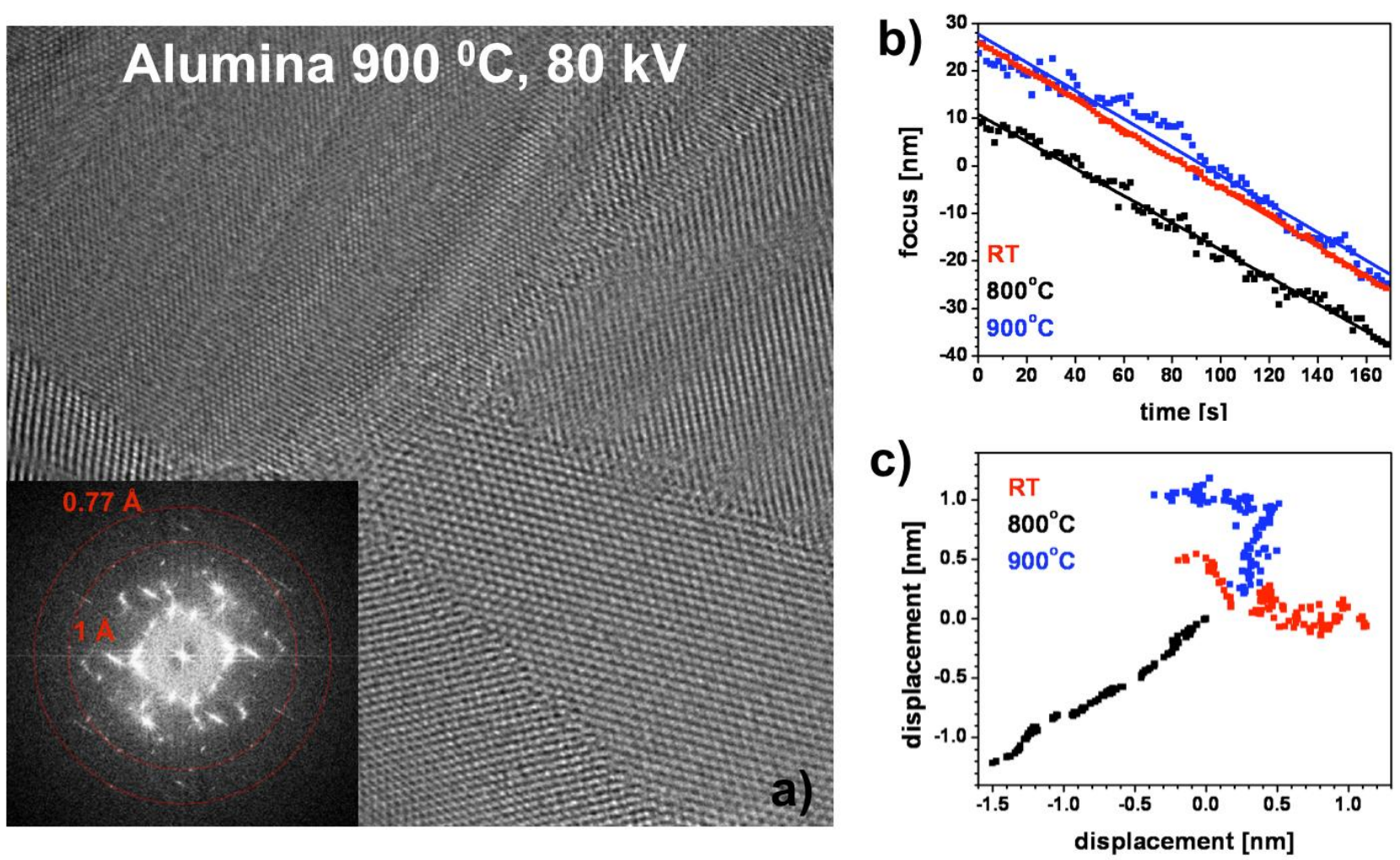

Figure 2. Drift measurements of a MEMS-based heating holder from Protochips in the TEAM 0.5 microscope. The measurements show that even the unprecedented TEAM 0.5 performance complies with observations at elevated temperatures. (a) TEM image of an alumina sample at $900{ }^{\circ} \mathrm{C}$ in the microscope base vacuum with its Fourier transform inserted. Alumina should be thermally stable under those conditions. (b) The drift along the electron beam direction is analyzed by the corresponding focus change. The focus change is measured in an exit wave reconstruction process from a focus series of images (Barton et al., 2012). Deviations from linear regression marks drift of a thermally stable sample. (c) The lateral drift is measured as the sample displacement in two orthogonal directions by cross-correlation of successive images. As drift depends on the thermal history, drift at different temperatures is expected to differ. The measurements show that thermal drift can reach a level of $1-1.5 \mathrm{~nm}$ over ca. $3 \mathrm{~min}$, which is sufficient for the exit wave reconstruction method, even at as high temperature as $900{ }^{\circ} \mathrm{C}$. 


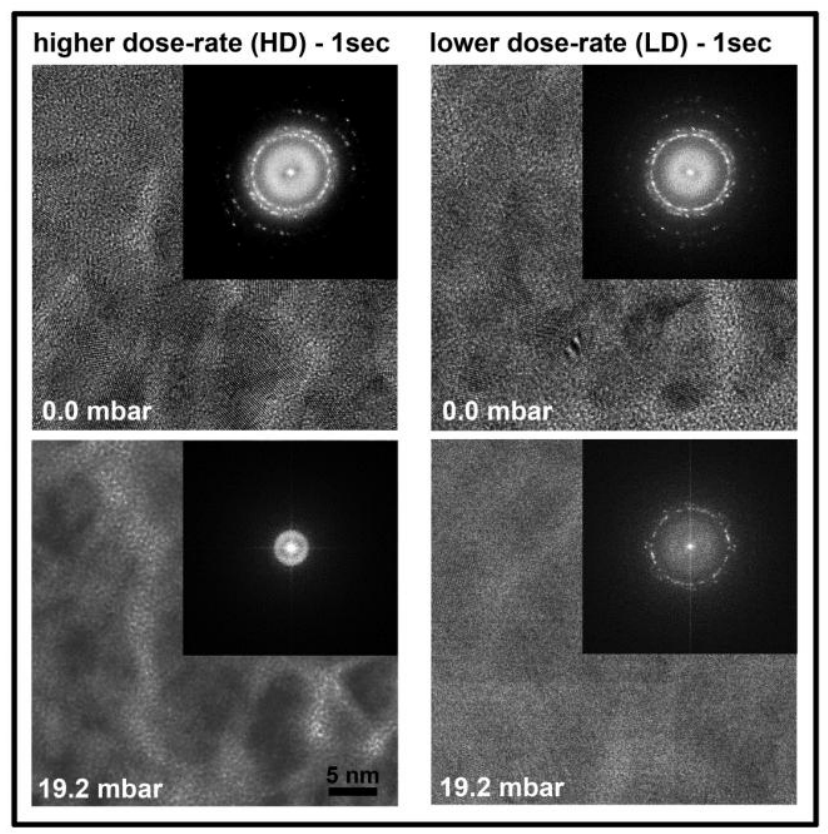

lower dose-rate $\left(\mathrm{LD}_{10 \mathrm{~s}}\right)-10 \mathrm{sec}$ higher dose-rate $\left(\mathrm{HD}_{0.1}\right)-0.1 \mathrm{sec}$
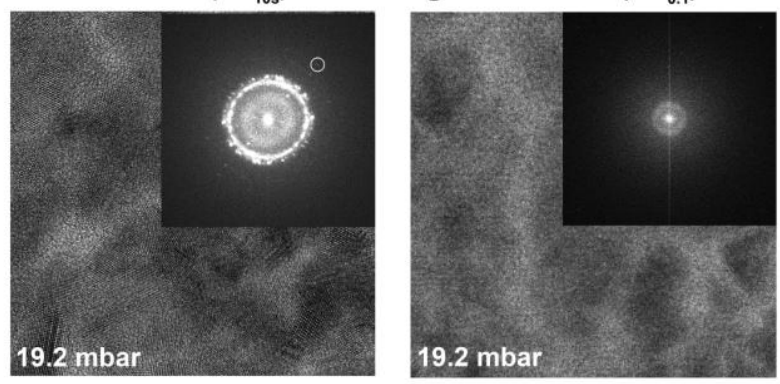

Figure 3. Investigation of achievable TEM resolution in gas environments under different electron illumination conditions. High-resolution TEM images of $\mathrm{Au} / \mathrm{C}$ cross-grating specimen are shown and their fast Fourier transforms (FFT) are inserted. From the FFT, the maximum transferred reciprocal lattice vector is taken as measure for the inverse resolution limit, as described in (Jinschek and Helveg, 2012). The TEM images were acquired in situ during the exposure of the specimen to 0.0 and $19.2 \mathrm{mbar} \mathrm{N}_{2}$. The electron illumination used a primary electron energy of $300 \mathrm{keV}$ and with a higher electron dose-rate $\left(r=10^{4} \mathrm{e}^{-} / \AA^{2} \mathrm{~s}\right)$ and lower electron dose-rate $\left(r=10^{3} \mathrm{e}^{-} / \AA^{2} \mathrm{~s}\right)$. All four upper images (in frame) were acquired with the same exposure time $t=1 \mathrm{~s}$, resulting in a total dose $D=10^{4} \mathrm{e}^{-} / \AA^{2}$ (left column) and $D=10^{3} \mathrm{e}^{-} / \AA^{2}$ (right column). The additional micrographs (below the frame) were acquired under the lower dose-rate and $t=10 \mathrm{~s}$ as well as the higher dose-rate and $t=0.1 \mathrm{~s}$, corresponding to the same total dose of $10^{4}$ 
$\mathrm{e}^{-} / \AA^{2}$ (left column) and of $10^{3} \mathrm{e}^{-} / \AA^{2}$ (right column). Adapted from (Jinschek and Helveg, 2012). 


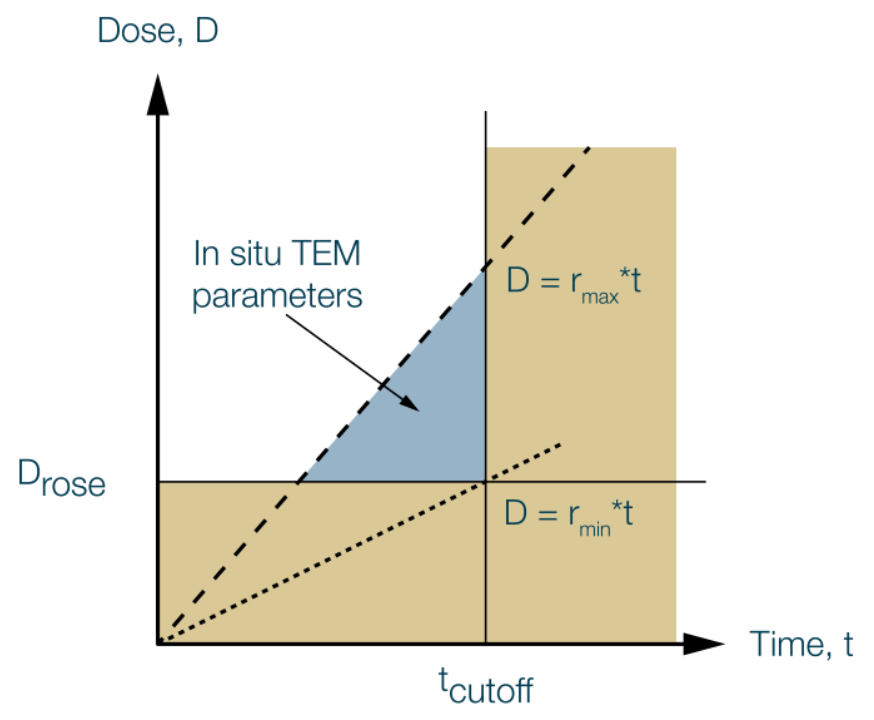

Figure 4. Schematics of the parameter window of dose, dose-rate and exposure time enabling high-resolution TEM observations under non-invasive illumination. 


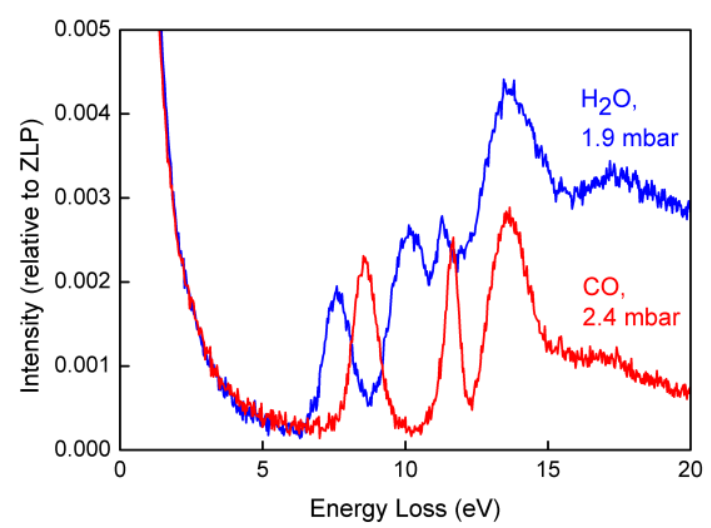

Figure 5: Electron energy loss spectra of (a) $\mathrm{CO}$ at 2.4 mbar and (b) $\mathrm{H}_{2} \mathrm{O}$ at 1.9 mbar. The primary electron energy is $80 \mathrm{keV}$ and the energy resolution, defined as the full width at half maximum of the zero loss peak, is ca. $0.6 \mathrm{eV}$. In the spectra, the zero loss peak (ZLP) is identified as the more intense peak and calibrated to $0 \mathrm{eV}$. The spectrum intensity has been scaled relative to the ZLP intensity. 


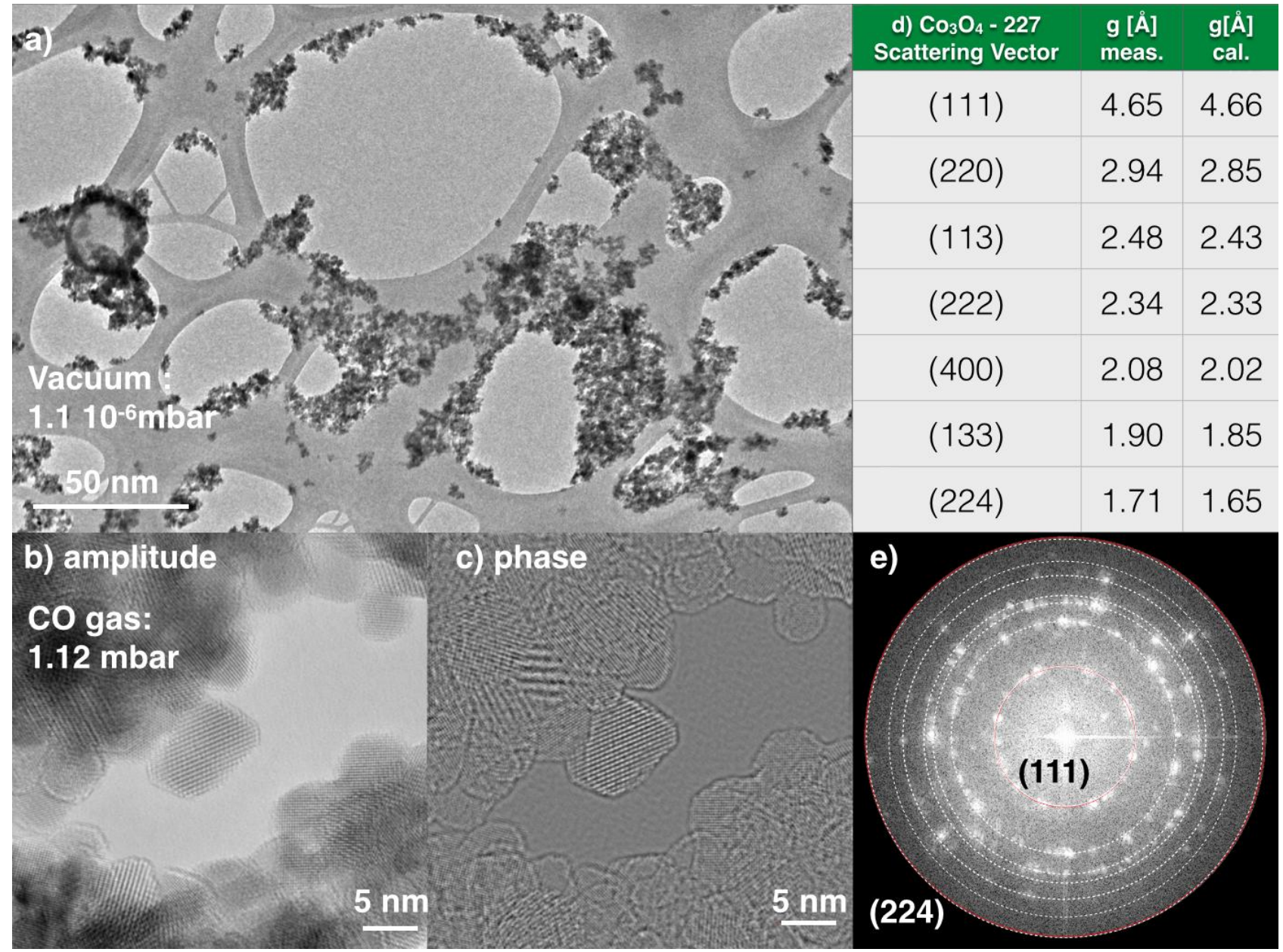

Figure 6: Overview of the investigated $\mathrm{Co}_{3} \mathrm{O}_{4}$ catalyst material. (a) TEM image of the nanocrystalline $\mathrm{Co}_{3} \mathrm{O}_{4}$ dispersed on a lacey carbon film. The image is acquired in the microscope base vacuum of $1.1^{*} 10^{-6}$ mbar. (b) Amplitude and (c) phase of an exit wave reconstruction from a focal image series of 30 images. (b) and (c) are both components of the in-line hologram. The $\mathrm{Co}_{3} \mathrm{O}_{4}$ nanocrystals were under exposure to $1.1 \mathrm{mbar} \mathrm{CO}$ during image recording. (d) Calculated crystal lattice planes and spacings of $\mathrm{Co}_{3} \mathrm{O}_{4}$ in space group 227 (Fd-3mm). (e) Nanodiffractogram obtained as the Fourier transform of the entire exit wave function. The $\mathrm{Co}_{3} \mathrm{O}_{4}$ crystal lattice information from (d) is superimposed to index diffraction spots. A resolution of $1.6 \AA$ is set by the visible numerical aperture. 

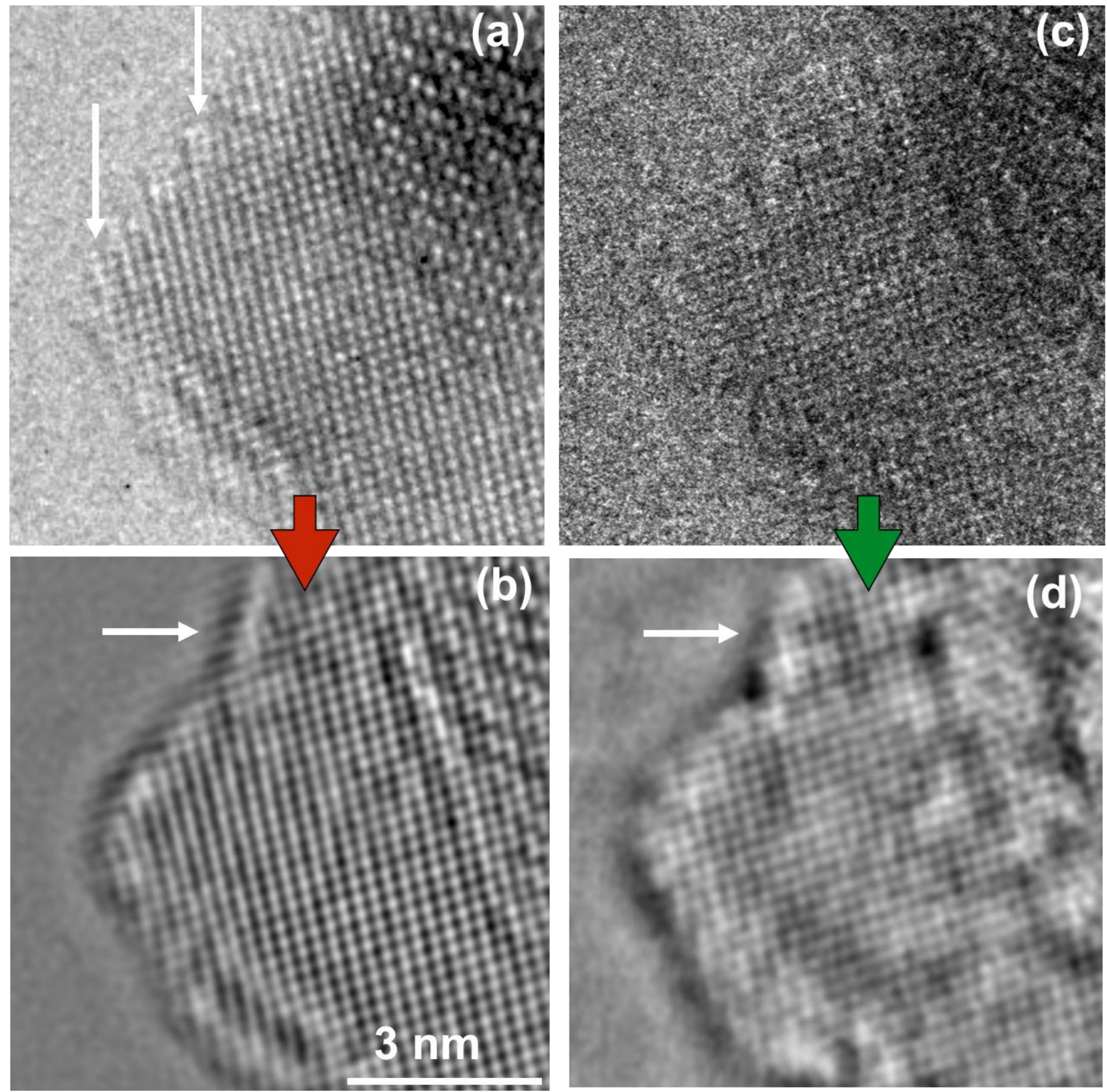

Figure 7: Effect of the electron illumination on surface structure and dynamics. (a,c) Single TEM images. (b,d) Phase images of the reconstructed electron exit wave function. All images recorded with the $\mathrm{Co}_{3} \mathrm{O}_{4}$ specimen during exposure to 2.1 mbar $\mathrm{CO}$. White arrows in (a) indicate features that undergo dynamic changes in successively recorded images in a time series, as demonstrated in the supplementary movie (Co3O4.mov). Dose rates and total doses are vastly different: Dose-rate $(a, b): 700 \mathrm{e}^{-} / \AA^{2} \mathrm{~s},(\mathrm{c}, \mathrm{d}): 30 \mathrm{e}^{-} / \AA^{2} \mathrm{~s}$, Total dose (b): $84000 \mathrm{e}^{-} / \AA^{2},(\mathrm{~d}): 4200 \mathrm{e}^{-} / \AA^{2}$. In (b), the white arrows point out a streaky contrast at the 
catalyst surface which is absent in the same area in (d). As (b) and (d) differ by the electron dose-rate, the streaky contrast is attributed to beam-induced atom motion.
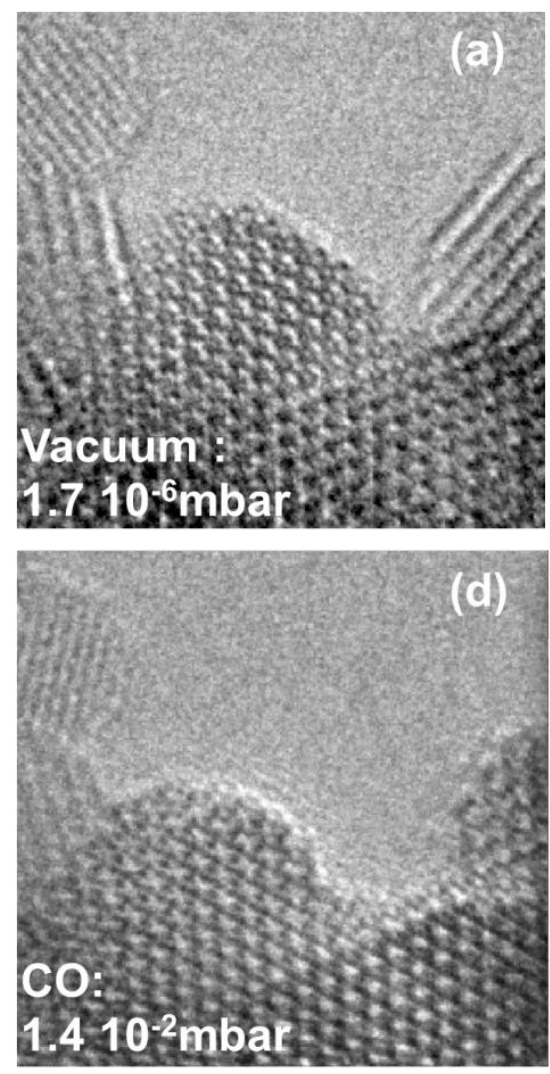
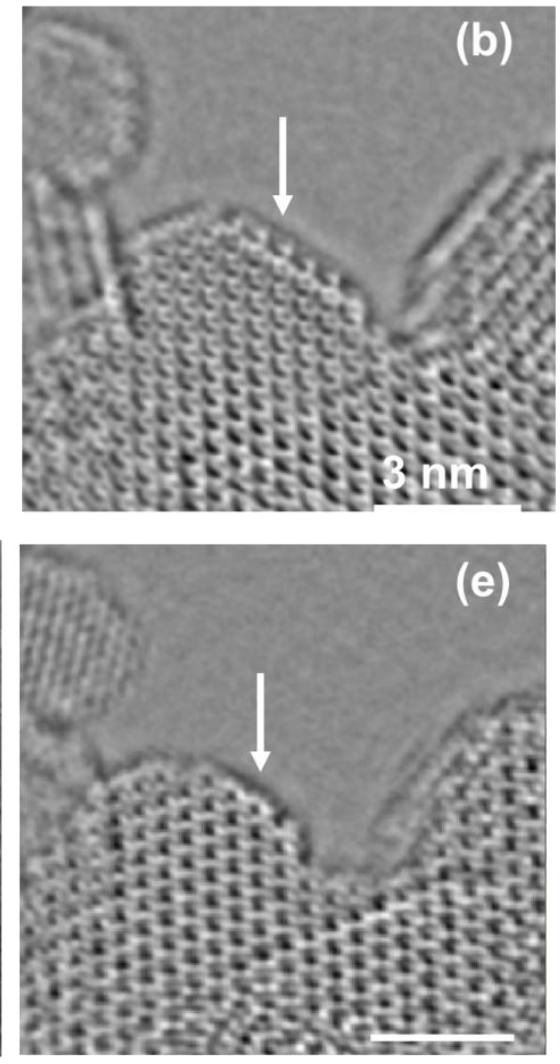
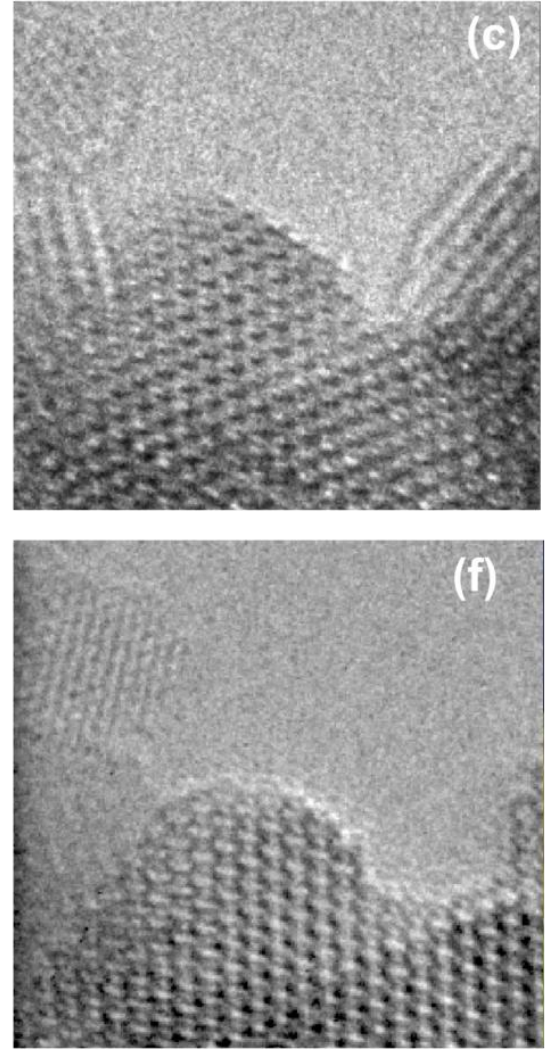

Figure 8: Comparison of $\mathrm{a} \mathrm{Co}_{3} \mathrm{O}_{4}$ surface in vacuum (a-c) and under exposure to $\mathrm{CO}(\mathrm{d}-\mathrm{f})$. (a-c) Microscope base vacuum of $1.6^{*} 10^{-6} \mathrm{mbar}$, and (d-f) $1.6{ }^{*} 10^{-2} \mathrm{mbar}$ CO. (b) and (e) show phase images reconstructed from focal series of 30 images obtained at an electron dose-rate of $300 \mathrm{e} / \AA^{2} \mathrm{~s}$ in vacuum and $\mathrm{CO}$, respectively. The white arrows indicate the surface transformation. $(\mathrm{a}, \mathrm{d})$ and $(\mathrm{c}, \mathrm{f})$ are single images acquired before and after the focal series, respectively. CO was admitted to ca. $1^{*} 10^{-2}$ mbar at least 8 min prior to (d). 


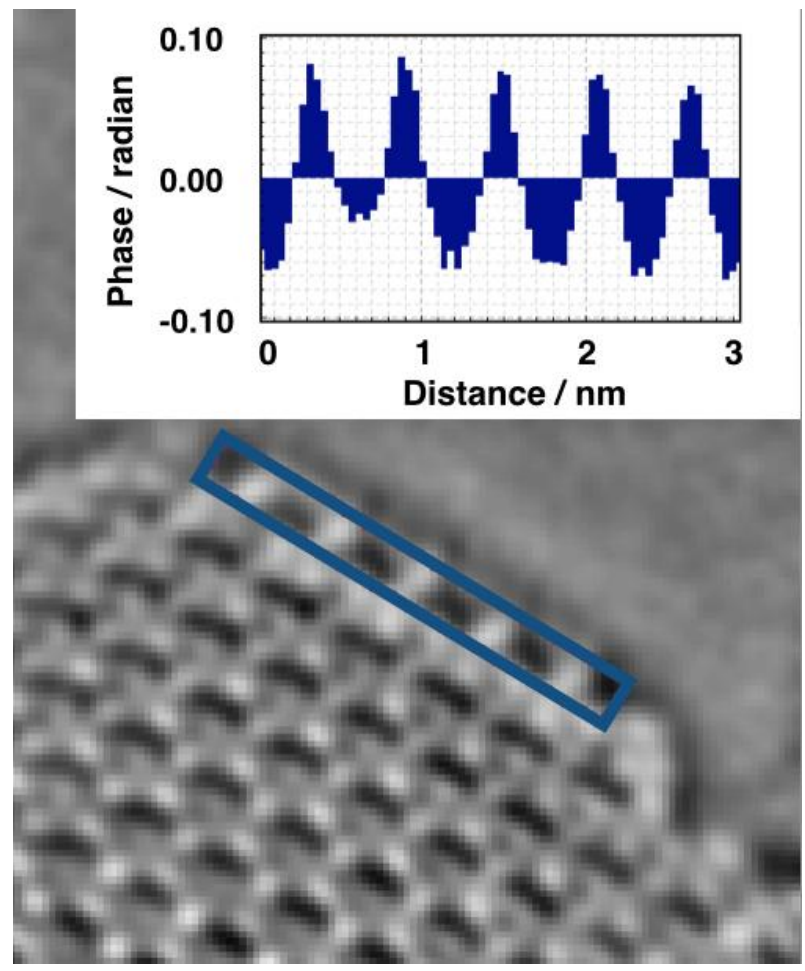

Figure 9: Linescan of phase along the surface of the $\mathrm{Co}_{3} \mathrm{O}_{4}$ crystallite in Fig. 8(b). 

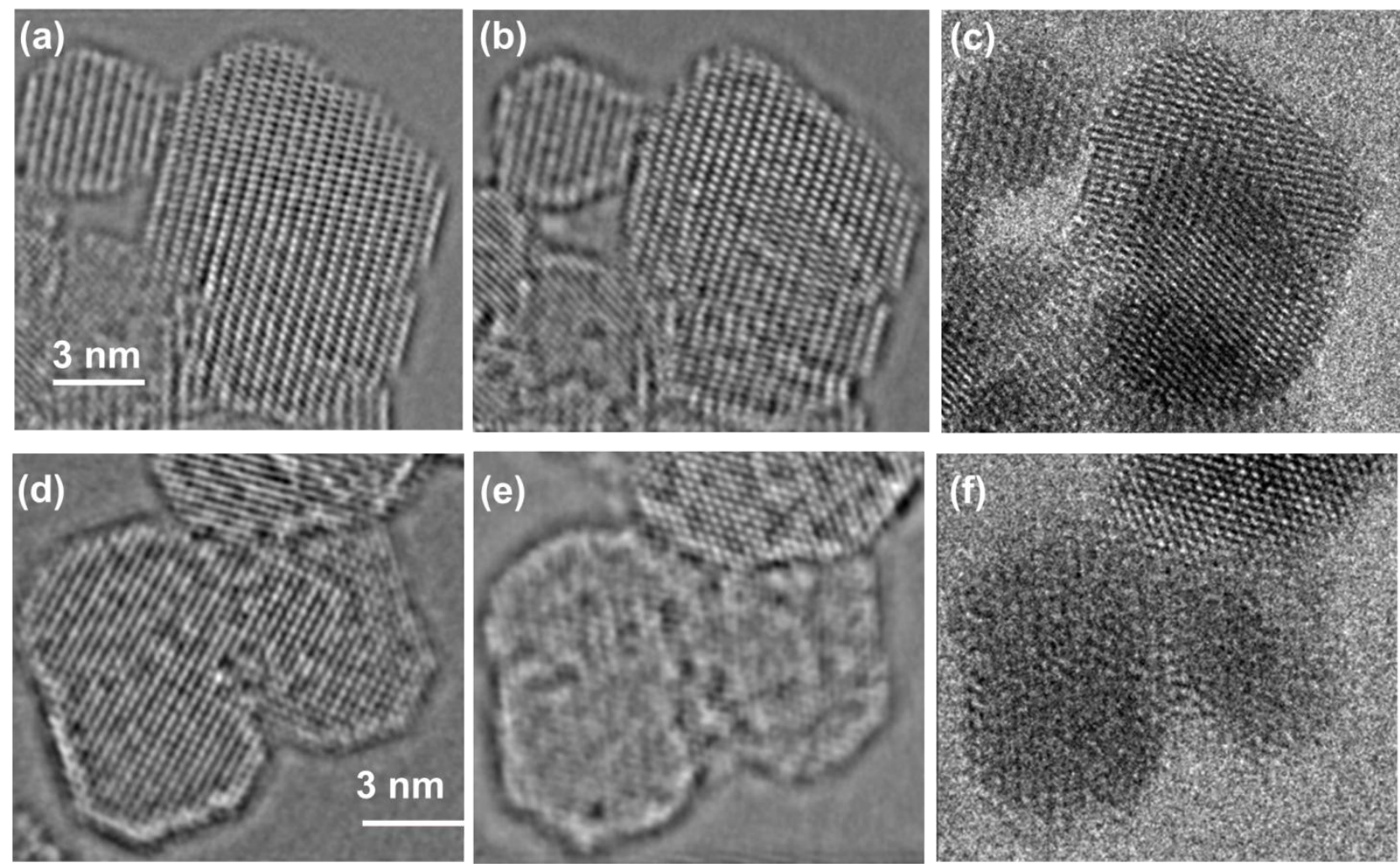

Figure 10: $\mathrm{Co}_{3} \mathrm{O}_{4}$ nanocrystals during exposure to $\mathrm{H}_{2} \mathrm{O}$. All images are obtained from focal series recorded in situ during continued exposure to $\mathrm{H}_{2} \mathrm{O}$ at $2.4^{*} 10^{-4}$ mbar (a,d) and $1.2^{*} 10^{-2} \mathrm{mbar}(\mathrm{b}, \mathrm{c}, \mathrm{e}, \mathrm{f}) .(\mathrm{a}, \mathrm{b}, \mathrm{d}, \mathrm{e})$ are the phase images of in-line holograms reconstructed from focal series of 30 images. These phase images represent two different areas on the sample and reveal the effect of different $\mathrm{H}_{2} \mathrm{O}$ pressures. (c,f) Single images from the focal series corresponding to $(b, e)$. After the acquisition of the focal series corresponding to (a,d), the $\mathrm{H}_{2} \mathrm{O}$ pressure was increased from $6.0^{*} 10^{-4}$ mbar to $1.2^{*} 10^{-4}$ mbar over 10 min and maintained for $1 \mathrm{~min}$ prior to the focal series acquisition corresponding to (b,c,e,f). Prior to $\mathrm{H}_{2} \mathrm{O}$ dosage, the sample was exposed to $\mathrm{CO}$, and subsequently a base vacuum of $2^{*} 10^{-6} \mathrm{mbar}$. The dose-rate is $280 \mathrm{e}^{-} / \AA^{2} \mathrm{~s}$. 

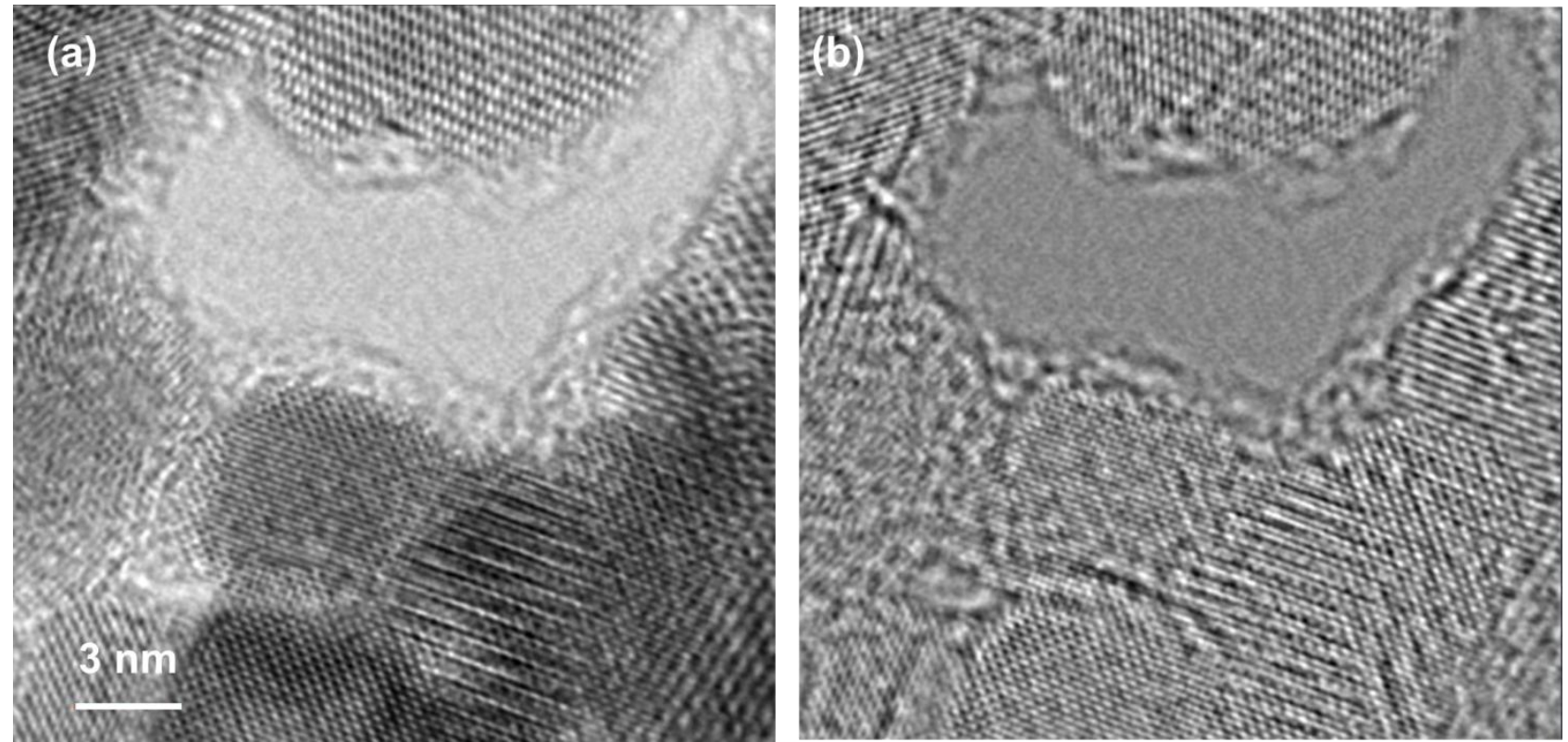

Figure 11: Growth of a contamination layer on the $\mathrm{Co}_{3} \mathrm{O}_{4}$ surfaces upon prolonged exposure to $\mathrm{H}_{2} \mathrm{O}$. (a) Amplitude and (b) phase of the in-line hologram reconstructed from a focus series of 30 high-resolution TEM images. The gas exposure time at this pressure was $\sim 20$ minutes. The dose rate is $200 \mathrm{e}^{-} / \AA^{2} \mathrm{~s}$.

Supplementary Movie: The movie is compiled of 30 consecutive single images recorded with $700 \mathrm{e}^{-} / \AA^{2} \mathrm{~s}$ at a constant overfocus of about $8 \mathrm{~nm}$. The single images were acquired with $1 \mathrm{~s}$ exposure of the CCD but are displayed by $0.1 \mathrm{~s}$ per image. Thus, the image sequence in the movie is accelerated. The image width is $11 \mathrm{~nm}$. 